\title{
Do Olhar do Outro \\ À Sublimação de se Constituir Negro ${ }^{1}$
}

\section{Isildinha Baptista Nogueira ${ }^{2}$}

As personagens de uma tragédia deparam-se inevitavelmente com os Deuses ou com diversas situações da Vida, em fatos que os levam à fatalidade.

A personagem principal da tragédia costuma terminar morta ou destruída moralmente. Porém, existem as chamadas tragédias de sublimação, onde a personagem consegue passar a herói, ao superar todas as adversidades. Assim tem sido a aventura de constituir-se negro, superar, sublimar, lutar para nos tornarmos semelhantes, num mundo onde ser branco é ter um lugar e ser negro é estar excluído da sua própria humanidade.

Sobreviventes de um drama que não refaz seu script, antes o mantém por séculos, a despeito das adversidades, das desconstruções, nos recusamos a morrer. Lamentavelmente, quando não sucumbimos às estruturas de poder, somos mortos por ela ou levados a tirar a própria vida, drama que se repete há séculos desde a escravidão, sem que nada efetivo seja feito para por um fim nessa tragédia que se atualiza a cada dia; jovens negros são assassinados pelas estruturas de poder ou se suicidam por não suportarem a dor da exclusão.

Desde criança eu sentia preconceito de cor. Queria o Curso de Sociologia para me proteger do preconceito.

[...] Eu fui para a Escola de Sociologia porque eu tinha sofrimento, tinha dor e eu queria saber o que me causava tanto sofrimento. E eu colocava que eram condições exteriores a mim. Então eu pensei que a sociologia iria me esclarecer sobre os motivos do meu sofrimento [...] e estando no curso, eu

\footnotetext{
${ }^{1}$ Este trabalho foi apresentado no Fórum violência e alteridade no I Simpósio Bienal "O mesmo, o outro: Psicanálise em movimento" da Sociedade Brasileira de Psicanálise de São Paulo.

${ }^{2}$ Profa. Dra. em Psicologia pela USP, formação em psicanalise nos Ateliers de Psychanalyse com Radmila Zygouris.
} 
estava no segundo ano, pela primeira vez em minha vida eu ouvi falar de Freud, em sublimação e fatores internos. Então eu disse, não é sociologia que eu tenho que estudar, eu tenho que estudar é psicanálise e Freud (BICUDO: 1994). ${ }^{3}$

Do sofrimento e da dor nasce a Psicanalista Virgínia Bicudo, mulher negra, uma das fundadoras da Sociedade Brasileira de Psicanálise de São Paulo, que, em alto e bom tom, trouxe com ela essa questão para a psicanálise e para os psicanalistas; onde ficou essa Voz que em meados da década de 40 soou?

Soou sem "escuta analítica", sem parceria, mas pairou como um eco que o tempo não sufocou. Será que agora a Sociedade de Psicanálise pode fazer essa "escuta", carente de lugar?

A morte levou a mulher negra psicanalista. Teve sua produção, quiçá restrita ao espaço da biblioteca desta casa, seu retrato no portal, como uma guardiã secreta de tudo o que produziu aqui ao longo dos anos, sem que suas questões pudessem ser ouvidas, que dirá "escutadas".

Espaço reservado aos iniciados desse conhecimento, Psicanálise, que permaneceu e permanece à disposição de uma elite branca que até aqui não pode fazer a escuta dessa mulher negra/psicanalista. Na década de 50 silenciou, ou melhor, foi silenciada, pela indiferença em relação a essa questão.

Mas o eco de sua voz nos alcançou. Será esse o momento? Será, Virgínia, que seus pares vão te ouvir, nos ouvir, e escutar o que você disse lá? Será que vão nos enxergar como semelhantes e não como uma excepcionalidade, uma exceção, uma curiosidade? Virgínia buscou, lutou, sublimou, sob orientação de Donald Pierscen, defendeu o que hoje nomeamos sua dissertação de Mestrado "Estudos de Atitudes Raciais de Pretos e Mulatos em São Paulo", nas Ciências Sociais. Seu esforço em entender como se davam

3 Gomes, Janaina Damaceno. Os Segredos de Virgínia: estudos de atitudes raciais em São Paulo. (1945-1955). São Paulo, 2013:49. 
as relações sociais sob a égide do racismo. Tinha uma firme convicção de que a psicanálise a ajudaria a avançar nessa questão.

No início escolhi a psicanálise porque nela encontrei abertura para o existencial social; eu podia ter uma formação como psicanalista e ter um lugar de trabalho no social. Só aos poucos fui descobrindo que o ser psíquico é mais importante que o ser social: é o que comanda a integração com o social e com o físico [...] (Haudenschild. S/C). ${ }^{4}$

O seu trabalho de Tese, em 1945, foi muito criticado porque a interpretação da Academia, nessa época, era de que não existia preconceito racial; foi acusada de não deixar claro o preconceito de cor e discriminação, uma polêmica que fica sob a responsabilidade de quem o lê; há quem afirme que está claro e há os que a acusam de não redimir os negros.

Conta-nos Janaina D. Gomes, em sua Tese, que quando Virgínia morreu, na sua mesa de trabalho estava o livro de Relações Raciais de Negros e Brancos em São Paulo. Essa questão esteve com ela todo o tempo. ${ }^{5}$

Quisera eu, mulher negra/psicanalista, ter um segundo que fosse do seu brilhantismo e conhecimento, para fazer contigo uma parceria nessa luta que você começou na construção de um discurso que pudesse falar de nós "negros”, de forma inteligível à psicanálise, para além de nossa condição de mulher negra/psicanalista. Que ultrapassasse a esfera da democracia liberal, que nos prometeu uma igualdade de deveres enquanto cidadãos cumpridores de seus deveres (pagar impostos, votar etc.) mas jamais uma semelhante como seres humanos com direito a um lugar. ${ }^{6}$

Gomes, J. Damaceno, op.cit. p. 51.

GOMES, Janaina Damaceno, op.cit. p. 136.

6 Mbembe, Achille. Crítica da Razão Negra. Ed. N-1. Edições 2018. Título original: Critique de la raison negre. Editions La Découverte. Paris, 2013, 1018. 2013, 2015, 2018. 
Uma liberdade, como nos diz $\mathrm{MBEMBE}^{7}$, que não nos permite compartilhar direitos, prazeres, trabalho, nem as dores, muito menos a morte; podemos ser assassinados aos olhos da lei, sem que seja de fato um crime, que permanecerá sem reparação possível, num acordo cordial perverso; a morte dos negros não importa.

Em seu livro $\mathrm{MBEMBE}^{8}$ cita Alexis de Torqueville que nos diz que o preconceito racial ... parece aumentar à proporção que os negros deixam de ser escravos e a desigualdade se grava nos costumes, à medida que se apaga nas leis. A abolição do princípio de escravidão não significa necessariamente a libertação dos escravos e a igualdade distributiva. Apenas contribui para fazer deles 'desgraçados destroços', destinados à destruição.

Sendo a cultura do povo africano oral, tribal, sem registro, sua humanidade não tem uma história formal, registrada como se fossem alheios ao trabalho e às leis.

Do olhar do Outro, um estereótipo se constrói; logo somos aprisionados no corpo negro, tornando tal estereótipo uma realidade psicológica.

A mancha negra é a marca da imperfeição, o signo que atravessa os mais diferentes códigos sociais, pois o sentido que porta será sempre o da exclusão. É por isso que a luta do negro será sempre a luta para ser incluído; mas essa é uma luta eterna pois, no limite, a inclusão nunca é obtida pelo negro, uma vez que o corpo negro sempre permanecerá como marca de exclusão.

No meu trabalho de Tese ${ }^{9}$ penso que a estrutura social acaba por se reproduzir no corpo humano, de forma a dar-lhe um sentido em particular, o que certamente irá variar de acordo com os mais diferentes sistemas sociais, como nos disse J.C. RODRIGUES:

Como qualquer outra realidade do mundo, o corpo humano é socialmente concebido. ${ }^{10}$

Idem, ibidem, p.153.

Idem, ibidem.

9 NogueIRA, I.B. Significações do Corpo Negro. Doutorado em Psicologia. Universidade de São Paulo, 1998:40. 
A análise da representação social do corpo possibilita entender a estrutura de uma sociedade. A sociedade privilegia um dado número de características e atributos que deve ter o homem, sejam morais, intelectuais ou físicos; esses atributos são, basicamente, os mesmos para toda a sociedade, embora possam se nuançar para diferentes grupos, classes ou categorias, que fazem parte da sociedade.

O corpo humano, para além de seu caráter biológico, é afetado pela religião, grupo familiar, classe, cultura e outras intervenções sociais.

Assim cumpre uma função ideológica, isto é, a aparência funciona como garantia, ou não, da integridade de uma pessoa, em termos de grau de proximidade ou de afastamento em relação ao conjunto de atributos que caracterizam a imagem dos indivíduos em termos do espectro das tipificações. É assim que, em função da aparência (atributos físicos), alguém é considerado como um indivíduo, capaz ou não de cometer uma transgressão (atributos morais), por exemplo.

Isto significa que o corpo está investido de crenças e sentimentos que estão na origem da vida social mas que, ao mesmo tempo, não estão submetidas ao corpo:

O mundo das representações se adiciona e se sobrepõe a seu fundamento natural e material, sem provir diretamente dele. ${ }^{11}$

A utilização do corpo como sistema de expressão não tem limites. ${ }^{12}$

De fato, os atributos físicos que caracterizam o negro e, mais particularmente, a cor da pele, expressam as representações que, historicamente, associam a essas características físicas atributos morais e/ou intelectuais que vão corresponder, no espectro das tipificações sociais, aquilo que se instaura na dimensão do distante, ou seja, aquilo que expressa o que está além do conjunto dos valores nos quais os indivíduos se reconhecem.

\footnotetext{
Rodrigues, J.C. Tabu do Corpo. Rio de Janeiro. Ed. Achiame, 1983:31.

RODRIGUES, J.C. op.cit, 1983:46.

Idem, ibidem, 1983:97.
} 
Nessa rede, negro e branco se constituem como extremos, unidades de representação que correspondem ao distante - objeto de um gesto de afastamento - e ao próximo, objeto de um gesto de adesão.

Dessa forma, a rede de significações atribui ao corpo negro a significância daquilo que é indesejável, por contraste com o corpo branco, parâmetro da auto-representação dos indivíduos. Como diz RODRIGUES, a cultura necessita do negativo, do que é recusado, para poder instaurar, positivamente, o desejável. Tal processo inscreve os negros num paradigma de inferioridade em relação aos brancos

O indivíduo branco pode se reconhecer em um "nós" em relação ao significante "corpo branco" e, consequentemente, com os atributos morais e intelectuais que tal aparência expressa, na linguagem da cultura, e que representam aquilo que é investido das excelências do sagrado.

O negro, no entanto, é aquele que traz a marca do "corpo negro", que expressa, escatologicamente, o repertório do execrável que a cultura afasta pela negativização.

Vítima das representações sociais que investem sua aparência daqueles sentidos que são socialmente recusados, o negro se vê condenado a carregar na própria aparência a marca da inferioridade social. Para o indivíduo negro, o processo de se ver em um "nós" em relação às tipificações sociais inscritas no extremo da desejabilidade, esbarra nessa marca - o corpo - que lhe interdita tal processo de identificação; ao mesmo tempo, a cultura incita-o a aderir aos signos de desejabilidade, pela injunção, própria das estruturas da cultura, que resulta do fato de que os signos desse sistema são introjetados nos indivíduos no processo de socialização.

Dessa forma a cultura que constitui a categoria "negro" enquanto um signo produz para o indivíduo negro, uma posição de ambivalência: oferece-lhe um paradigma - o da brancura - enquanto lugar de identificação social; no entanto, por representar justamente o outro da brancura tal identificação é evidentemente interditada, pois na rede de tipificações como se viu em RODRIGUES, deve ser mantida. 
Preso às malhas da cultura, o negro trava uma luta infinda na tentativa de se configurar como indivíduo no reconhecimento de um "nós". Seu corpo negro, socialmente concebido como representando o que corresponde ao excesso, ao que é outro, ao que extravasa, significa, para o negro, a marca que a priori o exclui dos atributos morais e intelectuais associados ao outro do negro, ao branco: o negro vive cotidianamente a experiência de que sua aparência põe em risco sua imagem de integridade.

Se a cultura lhe atribui uma natureza que é da ordem do inaceitável, esses sentidos são introjetados pelo negro e vão, necessariamente, produzir configurações psíquicas particulares.

Nesse processo em que a cultura o captura, o negro recusa sua própria imagem e permanece cativo do fantasma da inferioridade, de que seu corpo é, socialmente, a marca.

FANON $^{13}$, comentando as observações de Sartre sobre o racismo, diz:

Jean Paul Sartre a oublié que le nègre souffre dans son corps autrement que le blanc. Entre le blanc et moi, il y a irrémédiablement um rapport de transcendance. ${ }^{14}$

É essa dimensão singular que torna a condição de negro impossível de ser simetrizada à condição de branco que produz, para o negro, essa experiência de sofrer o próprio corpo Não conseguindo se ver incluído, o negro acaba por se excluir como uma alternativa para eliminar aquilo que é impossível de ser eliminado, "seu próprio corpo", sua própria condição de sujeito.

13 FANON, F. Peu noir, masques blancs. Paris, Seuil, 1952:112.

14 Idem. Jean Paul Sartre esqueceu que o negro sofre no seu corpo ao contrário que o branco. Entre o branco e eu, tem irremediavelmente uma relação de transcendência. 1983:97. 
Pode haver algo mais complexo do que ser portador de um corpo negro, portanto marcado pelos significados a ele associados, a partir do que conhecemos a respeito da gênese da imagem do corpo?

Lembremos que é num processo inconsciente que esta gênese se dará como resultante de um duplo processo identificatório e projetivo: "ser o sujeito sendo concomitantemente o outro e ser o outro não sendo o próprio sujeito".

Se o que constitui o sujeito é o olhar do outro, como fica o negro que se confronta com esse olhar, que mostra reconhecer nele o significado que a pele negra traz, enquanto significante?

Para além de seus fantasmas inerentes ao ser humano, resta ao negro o desejo de recusar esse significante, que representa o significado que ele tenta negar, negando-se dessa forma a si mesmo, pela negação do próprio corpo. Negar e anular o próprio corpo nos torna o sujeito "outro", visto que só existimos como sujeito em relação ao outro, à alteridade. Ser sujeito é, portanto, ser outro. E ser outro é não ser o próprio sujeito, no caso negro.

Evidentemente, no confuso processo porque passam os negros, ser sujeito no outro significa não ser o real do seu próprio corpo, que deve ser negado para que se possa ser o outro. Mas esta imagem de si, forjada na relação com o outro - e no ideal da brancura - não só não guarda nenhuma semelhança com o real de seu corpo próprio, mas é por este negada, estabelecendo-se aí uma confusão entre o real e o imaginário.

Essa confusão despersonaliza e transforma o sujeito num autômato: o sujeito se paralisa e se coloca à mercê da vontade do outro.

O sujeito assim fragilizado, envergonhado de si, se vê exposto a uma situação em que nada separa o real do imaginário, as fantasias estão "concomitantemente dentro e fora". SAMI-ALI diz: 
Na despersonalização, por conseguinte, o sujeito trata suas fantasias como objetos reais e trata os objetos reais como fantasias, duas particularidades que remetem, por ocasião da formação da imagem do corpo, aos inícios imprecisos da separação - mediatizada por uma projeção primordial - do dentro e do fora $O$ sujeito vive o mundo no corpo e o corpo no mundo; despersonalização e estranho inquietante são duas faces de um mesmo e único processo desrealizante. ${ }^{15}$

Estranho inquietante: inquietante porque é, ao mesmo tempo, estranho e familiar; esse é o conceito freudiano de "das Unheimlich”, um jogo dialético complexo, onde o familiar e o inquietante se localizam num mesmo e único objeto.

O estranho inquietante se dá ao nível do espaço sensorial, espaço esse organizado pela visão e que, dependendo das modificações que esse espaço possa vir a sofrer, pode tornar o objeto familiar estranhamente inquietante.

O que gera, no entanto, o pavor, não é o estranho que se opõe ao familiar, mas o reconhecimento do estranho no que antes era familiar, cujo caráter estranho não era, como tal, reconhecido devido a um processo de repressão. $\mathrm{O}$ estranho inquietante tem como característica, portanto, o fracasso da repressão que, ao falhar, abre espaço para o retorno inesperado do reprimido. Não se trata aqui de uma reação à função de diminuir uma percepção ameaçadora, mas de uma modificação do objeto que, de familiar, tornase estranho e, enquanto estranho, inquietante por sua coincidência com o objeto familiar. Unheimlich era o que deveria ter ficado oculto mas retorna, manifestando-se no objeto ao mesmo tempo presente e ausente.

O sentimento de estranho inquietante é um confuso retorno a uma organização espacial "onde tudo se reduz ao dentro e ao fora e onde o dentro é também o fora". 16

15 SAMI-Ali. Penser le Somatique, Imaginaire et Pathologie. Paris, Bordes, 1987.

16 Idem, ibidem, p. 34. 
Penso que esse movimento do estranho inquietante pode bem caracterizar o tipo de experiência que marca a relação do negro com o dia-a-dia no meio social. É impossível, para ele, não se perturbar com as ameaças aterradoras que lhe chegam via racismo. $\mathrm{O}$ racismo contrariamente ao preconceito, é a expressão da violência, é um ato, não uma interdição que se coloca a priori, como forma de proteger seja lá o que for.

Dentro desse universo de terror, mesmo que o negro acredite conscientemente que tais ameaças racistas não se cumprirão, o pavor não desaparece porque ele traz no corpo o significado que incita e justifica, para o outro, a violência racista. É justamente porque o racismo não se formula explicitamente, mas antes sobrevive num devir interminável enquanto uma possibilidade virtual, que o terror de possíveis ataques (de qualquer natureza, desde física à psíquica) por parte dos brancos, cria para o negro uma angústia que se fixa na realidade exterior e se impõe inexoravelmente.

Ainda que lançando mão de um arsenal lógico o negro possa considerar tais ameaças racistas que parecem grotescas, absurdas, totalmente incabíveis legalmente - já que criminosas em termos de direito civis - é mais forte que ele: o negro acaba sempre por sucumbir a todo um processo inconsciente que, alheio à sua vontade entrará em ação.

Essa confusão despersonaliza e transforma o sujeito num autômato: o sujeito se paralisa e coloca à mercê da vontade do outro.

O sujeito assim fragilizado, envergonhado de si, se vê exposto a uma situação em que nada separa o real do imaginário, as fantasias estão "concomitantemente dentro e fora".

Foram 320 anos de escravidão, a África perdeu 70 milhões de pessoas, do século XV ao XIX entre escravizados e mortos; no Brasil, entre o século XVI e XIX foram 12,5 milhões de escravos para aqui trazidos, portanto, um percentual de 36 a $46 \%$ dos escravizados. 
Apesar da capacidade da "humanidade" de se organizar entre avanços e recuos, nós, seres humanos, somos marcados pela ignorância e a estupidez, muito longe do respeito à "diversidade e a diferença".

A despeito das adversidades e especificidades, estamos construindo um discurso acerca de nós mesmos, negros, sobre a dor de pensar em nossos romances familiares, nosso lugar e condição no mundo nos humaniza, nos insere no seleto clube daqueles que podem pensar para crescer, avançar e se fortalecer.

As estruturas de poder e dominação não são alheias às psicanálises praticadas nos consultórios; toda mudança tem como base a possibilidade de nos olharmos sem autocomiseração;

Estre as várias contribuições de Virgínia Bicudo para entender os conflitos psicológicos vividos pelos negros conclui:

Vivendo o conflito entre ser "negro" e "não querer ser negro", equivalente ao conflito entre "ser mau" e "ser bom", as pessoas de cor sucumbem frequentemente ao conflito, auto-punitivamete, exibindo traços de personalidade que são tomados como confirmação dos estereótipos que lhe são dirigidos. Outros derivam o conflito na luta pela aquisição de características de branco, procurando instruir-se, elevar seu status". ${ }^{17}$

Virgínia Bicudo acreditou e eu acredito que a psicanálise nos instrumentalizou para pensarmos os seres, os tempos, a cultura; seremos nós, os psicanalistas, capazes de pensarmos a partir das nossas diferenças e crenças, os efeitos do racismo em nossas práticas clínicas, despidos de nossos preconceitos inerentes à nossa condição de humanos?

17 Gomes, Janaina Damaceno. Os Segredos de Virgínia: estudos de Atitudes Raciais em São Paulo. (1945-1955). São Paulo, 2013:145. 
Jurandir Freire Costa, no prefácio do livro de Neusa Santos Sousa "Tornar-se Negro", lembra-se de uma inscrição gravada no monumento às vítimas do Holocausto nazista, em Paris, onde está escrito: "Pardonne, mais n'aublie pas". ${ }^{18}$

“Perdoe, mas não esqueça".

O passado não pode ser refeito, o presente pode ser outro muito diferente desse que a história nos conta, como diria o Betinho (sociólogo brasileiro). Há um modo de contar a história e um modo de fazer a história.

Solano Trindade tem um lindo poema que ilustra quem somos, nós, os negros hoje.

Eu canto aos Palmares, sem inveja de Virgílio, de Homero e de Camões, porque o meu canto é o grito de uma raça, em plena luta pela liberdade!

\section{Referências}

FAnON, F. (1952:112). Peau Noir, Masques Blancs. Paris, Seuil.

GoMES, Janaina Damaceno. (2013:49) Os Segredos de Virginia: estudos de atitudes raciais em São Paulo (1945-1955). São Paulo.

Mbembe, Achille. ( 2013, 2015, 2018). Crítica da Razão Negra. Ed. N-1, edições 2018. Título original: Critique de la Raison Negre. Editions La Découverte. Paris.

NogueIRA, Isildinha Baptista. (1998:40). Significações do Corpo Negro. Doutorado em Psicologia. Universidade de São Paulo.

Rodrigues, J.C. (1983:31). Tabu do Corpo. Rio e Janeiro. Ed. Achiamé.

SAmi-Ali. (1987). Penser le Somatique, Imaginaire et Pathologie. Paris, Bordes.

SARTRE, J.P. (1948). Reflexões sobre o Racismo. Rio de Janeiro / São Paulo. Difel, 1078.

SouZA, Neusa Santos. (1983). Tornar-se Negro: as vicissitudes da identidade do negro brasileiro em ascenção social. Rio de Janeiro, Ed. Graal.

18 SouZA, Neusa Santos. Tornar-se Negro: as vicissitudes da identidade do negro brasileiro em ascenção social. Rio de Janeiro, Edições Graal, 1983. 